\title{
APLIKASI GIS UNTUK PEMETAAN POLA ALIRAN AIR TANAH DI KAWASAN BOROBUDUR
}

\author{
Oleh
}

Fr. Dian Ekarini, S.Si.

Balai Konservasi Peninggalan Borobudur

\section{ABSTRAK}

Candi Borobudur merupakan warisan nenek moyang yang harus dilestarikan dan dijaga keberadaannya. Unesco telah menetapkan Candi Borobudur masuk ke dalam WHL (World Heritage List) sebagai Warisan Budaya Dunia (World Cultural Heritage) dengan nomor 348 tertanggal 13 Desember 1991 dan kemudian diperbaharui menjadi nomor 592 tahun 1991, yang harus dilindungi oleh masyarakat dunia. Begitu banyak permasalahan dan tantangan yang harus dihadapi dalam melestarikan Candi Borobudur. terutama masalah air karena tempatnya yang terbuka. Setelah pemugaran kedua Candi Borobudur yang dilakukan oleh perintah Indonesia kerjasama dengan Unesco pada tahun 1973-1983, telah mulai dilakukan pemantauan/monitoring dan evaluasi terhadap hasil pemugaran termasuk salah satunya adalah mengenai masalah kondisi air bawah Candi Borobudur.

Penelitian ini dimaksudkan untuk mengetahui pola aliran air tanah di kawasan Candi Borobudur dengan memanfaatkan GIS (Geographic Information System). Dengan diketahuinya pola aliran air tanah ini dapat dijadikan acuan dikemudian hari untuk penelitian-penelitian lanjutan yang berhubungan dengan air tanah, contohnya adalah masalah pencemaran. Lokasi yang diambil untuk penelitian ini adalah Zona III Candi Borobudur yang merupakan tempat terdekat dengan Candi Borobudur yang berupa zona pengembang yang diperuntukkan bagi kawasan pemukiman penduduk, sehingga bisa diambil sampel sumurnya untuk penelitian.

Setelah kegiatan observasi di lapangan selesai, dilanjutkan pengolahan data dengan komputer menggunakan software AcrGIS 9.3 dan ArcView 3.3 untuk mendapatkan peta pola aliran air tanah di kawasan Borobudur. Dari hasil penelitian dapat diperkirakan kedalaman air tanah di komplek Candi Borobudur adalah 21,5 - 22 meter di bawah halaman candi. Di sekitar Candi Borobudur dapat diketahui pola aliran air tanahnya yaitu dari barat laut mengalir menuju ke arah tenggara sampai Sungai Progo. Selain itu dari penelitian ini, 2 sungai yang ada di lokasi penelitian yaitu Sungai Progo dan Sungai Elo masing-masing mempunyai 2 sifat aliran yaitu aliran efluen (sungai mendapat aliran air dari air tanah) dan influen (sungai memberi air kepada air tanah).

\section{A. Latar Belakang Masalah}

Candi Borobudur merupakan benda purbakala yang harus dilestarikan keberadaannya. Walaupun tidak termasuk salah satu keajaiban dunia namun Candi Borobudur menjadi World Heritage List (Daftar Warisan Dunia) dan secara kontinyu terus dipantau oleh UNESCO. Candi Borobudur terletak di Dusun Ngaran, Desa Borobudur, Kecamatan Borobudur, Kabupaten Magelang, Propinsi Jawa Tengah. Letaknya yang di atas bukit, sangat terbuka dan rawan terjadi kerusakan.

Setelah pemugaran Candi Borobudur yang kedua tahun 1973-1983 hasil kerjasama dari pemerintah Indonesia dengan UNESCO, mulai dilakukan pemantauan/monitoring dan evaluasi terhadap hasil pemugaran termasuk salah satunya adalah mengenai kondisi air bawah Candi Borobudur. Untuk mencegah dan menghindari rusaknya struktur candi yang diakibatkan oleh air tanah maka penting untuk dilakukan penelitian terhadap kondisi air tanah di bawah candi.

Air tanah adalah air yang terdapat dalam lapisan tanah atau bebatuan di bawah permukaan tanah. Air tanah merupakan salah satu sumber daya air yang keberadaannya terbatas dan kerusakannya dapat mengakibatkan dampak yang luas serta pemulihannya sulit dilakukan. Penyembuhan atau pengisian kembali air yang ada dalam tanah ini berlangsung akibat curah hujan, yang sebagian meresap ke dalam tanah, tergantung pada jenis tanah dan batuan yang mengalasi suatu daerah serta besarnya curah hujan yang meresap ke dalam bumi dalam jumlah besar atau kecil. Selain air sungai dan air hujan, air tanah juga mempunyai peranan yang sangat penting terutama dalam menjaga keseimbangan dan ketersediaan bahan baku air untuk kepentingan rumah tangga (domestik) maupun untuk kepentingan industri.

Kerusakan sumber daya air tidak dapat dipisahkan dari kerusakan di sekitarnya seperti kerusakan lahan, vegetasi dan tekanan penduduk. Ketiga hal tersebut saling berkaitan dalam mempengaruhi ketersediaan sumber air. Kondisi tersebut di atas tentu saja perlu dicermati secara dini, agar tidak menimbulkan kerusakan air tanah di kawasan sekitarnya. Beberapa faktor yang menyebabkan timbulnya permasalahan kerusakan air tanah ini adalah:

1. Pertumbuhan industri yang pesat di suatu 
kawasan disertai dengan pertumbuhan pemukiman akan menimbulkan kecenderungan kenaikan permintaan air tanah.

2. Pemakaian air beragam sehingga berbeda dalam kepentingan, maksud serta cara memperoleh sumber air.

3. Perlu perubahan sikap sebagian besar masyarakat yang cenderung boros dalam penggunaan air serta melalaikan unsur konservasi.

Adanya krisis air akibat kerusakan lingkungan, perlu suatu upaya untuk menjaga keberadaan/ketersediaan sumber daya air tanah salah satunya dengan memiliki suatu sistem monitoring penggunaan air tanah yang dapat divisualisasikan dalam data spasial dan atributnya. Dikarenakan selama ini tidak tersedia alat pemantau kondisi air tanah di lingkungan Candi Borobudur maka studi kali ini mengambil sampel air tanah penduduk di sekitar candi yaitu di sumur-sumur penduduk pada zona 3 yang mempunyai radius kurang lebih $3 \mathrm{~km}$ dari as candi.

Siklus hidrologi memegang peranan penting dalam penelusuran asal muasal air tanah. Sumber daya air tanah bersifat dapat diperbaharui (re-newable) secara alami, karena air tanah merupakan bagian yang tidak terpisahkan dari siklus hidrologi di bumi. Kejadian dan pergerakan air tanah bergantung pada kondisi fisik dan geologi setempat. Aliran air tanah merupakan salah satu bagian dari siklus hidrologi yang komplek. Dalam kenyataannya terdapat faktor pembatas yang mempengaruhi pemanfaatannya, baik dari segi kuantitas maupun kualitas. Dari segi kuantitas, air tanah akan mengalami penurunan kemampuan penyediaan apabila jumlah yang diturap melebihiumpan (ketersediaannya).

Curah hujan merupakan sumber utama dari air tanah selain sumber-sumber yang lain. Air hujan yang jatuh di permukaan bumi tidak seluruhnya mengalir sebagai aliran permukaan yang menuju ke sungai akan tetapi sebagian akan meresap ke dalam tanah melalui infiltrasi atau perkolasi sebagai umpan air tanah. Jumlah bagian air hujan yang masuk ke dalam tanah dipengaruhi oleh kondisi geologi, topografi, penggunaan lahan dan penutup lahan serta faktor lainnya. Oleh karena itu curah hujan bukan merupakan faktor utama yang mementukan potensi air tanah. Dengan kata lain daerah yang curah hujannya tinggi belum tentu mempunyai potensi air tanah yang tinggi pula.

\section{B. Tujuan Penelitian}

Tujuan dari penelitian/studi pada kali ini adalah memanfaatkan GIS (Geographic Information System) untuk mengetahui pola aliran air tanah di kawasan Borobudur.

\section{Manfaat Penelitian}

Manfaat penelitian kali ini adalah untuk memberikan informasi kepada pihak-pihak yang membutuhkan data tentang pola aliran air tanah di sekitar Candi Borobudur dan terutama kepada Balai Konservasi Peninggalan Borobudur untuk melakukan analisa selanjutnya dalam rangka melestarikan situs purbakala ini.

\section{Ruang Lingkup Penelitian}

Ruang lingkup studi ini adalah observasi lapangan dengan memanfaatkan GIS untuk memetakan pola aliran air tanah di kawasan Borobudur dengan mengukur koordinat $\mathrm{x}, \mathrm{y}$ dan kedalaman air sumur penduduk yang ada di zona 3 Candi Borobudur. Dipilihnya zona 3 sebagai lingkup penelitian karena zona 3 merupakan zona yang dihuni oleh penduduk sekitar dan dekat dengan Candi Borobudur yaitu mempunyai radius 3 $\mathrm{km}$ dan seluas kurang lebih $10,1 \mathrm{~km}^{2}$, sehingga diestimasikan mampu untuk merepresentasikan pola aliran air tanah di kawasan Candi Borobudur.

\section{E. Metode Pelaksanaan}

Metode pelaksanaan pada studi kali ini dilakukan dengan observasi lapangan untuk memetakan sumursumur penduduk di zona 3 Candi Borobudur dengan menggunakan alat GPS Magellan. Dengan alat tersebut akan terekam semua data koordinat $\mathrm{x}$, y dari titik-titik sampel yang diambil. Selain itu juga dilakukan pengukuran kedalaman muka air tanah sumur penduduk dengan menggunakan alat disto atau dengan manual menggunakan meteran. Untuk mengukur elevasi muka air tanah, karena data ketinggian tempat di kawasan zona 3 belum pernah dilakukan pengukuran secara terestris maka data ketinggian tempat menggunakan data sekunder yaitu data kontur tanah dari peta RBI digital keluaran Bakosurtanal tahun 2003 dengan skala 1 : 25.000. Data selanjutnya diolah dengan komputer menggunakan perangkat lunak (software) ArcGIS 9.3 dan ArcView 3.3.

Pada kawasan zona 3 ini akan diambil sampel sumur-sumur penduduk tiap dusun 1 sampel sumur untuk diukur koordinat dan kedalamannya. Dusun-dusun yang ada di kawasan zona 3 Candi Borobudur yang disurvai meliputi 46 dusun. Cara pengambilan sampel sumur penduduk dengan sistem Purposive Sampling (sampel dengan maksud) yaitu pengambilan sampel dilakukan hanya atas dasar petimbangan peneliti saja dan menganggap unsur-unsur yang dikehendaki telah ada 
dalam anggota sampel yang diambil.

Setelah sumur-sumur tersebut diukur kemudian dilakukan entry data dilanjutkan pengolahan dengan software ArcGIS dan ArcView untuk mendapatkan peta kontur air tanah (dpal). Selanjutnya, dari peta kontur air tanah kemudian dibuat pola arah aliran air tanah dengan jalan membuat garis arah yang tegak lurus $\left(90^{\circ}\right)$ terhadap garis kontur. Dalam pembuatan peta kontur air tanah, dikarenakan data tentang ketinggian tanah dari muka air laut tidak tersedia maka untuk pembuatan peta tersebut menggunakan data sekunder yaitu dari peta RBI digital dari Bakosurtanal keluaran tahun 2003 dengan skala 1 : 25.000 .

\section{F. Hasil Dan Pembahasan}

Sampel sumur penduduk yang diambil mewakili dusun-dusun yang ada di Zona III Candi Borobudur yang sebagian besar wilayahnya berada di 3 desa yaitu Desa Borobudur, Desa Wanurejo dan Desa Mendut. Dari survei di lapangan terdapat 80 titik sampel yang diambil. Ada sebagian kecil dari titik sampel yang tidak masuk Zona III tapi tetap diambil karena diperlukan untuk membantu dalam pembuatan kontur air tanah.

Pada Peta Sebaran Sampel Sumur Penduduk termasuk ke dalam zona 3 (ada 17 titik dari 80 titik) tetapi tetap dipakai karena titik-titik tersebut nantinya akan membantu dalam proses pembuatan kontur muka air tanah/kedalaman air tanah dan kontur air tanah.

Berdasarkan penelitian kedalaman muka air tanah dari sumur pengamatan terlihat bahwa dari sampel sumur yang diambil muka air paling dangkal yaitu 1,53 $\mathrm{m}$ di dusun Singkepan dan muka air paling dalam $16,12 \mathrm{~m}$ ada di dusun Santan tapi titik ini tidak termasuk zona 3, sedangkan yang termasuk dalam zona 3, sumur yang paling dalam ada di Mendut II yaitu 16,11 karena lokasi sampelnya berada di dekat sungai Elo yang mempunyai dinding yang curam dan dalam.

Berdasarkan hasil data yang diperoleh dari survei sumur-sumur penduduk di lapangan, data diolah menggunakan perangkat komputer untuk mendapatkan hasil peta pola aliran air tanah (streamlines) di kawasan Borobudur. Peta kontur air tanah adalah peta yang menghubungkan tempat-tempat yang mempunyai ketinggian muka air tanah yang sama (ketinggian dari permukaan air laut), sedangkan peta pola aliran air tanah adalah peta yang menunjukkan arah aliran air tanah. Pembuatan arah aliran air tanah adalah dengan menarik garis arah yang tegak lurus $\left(90^{\circ}\right)$ dengan kontur air t a n a h n y .

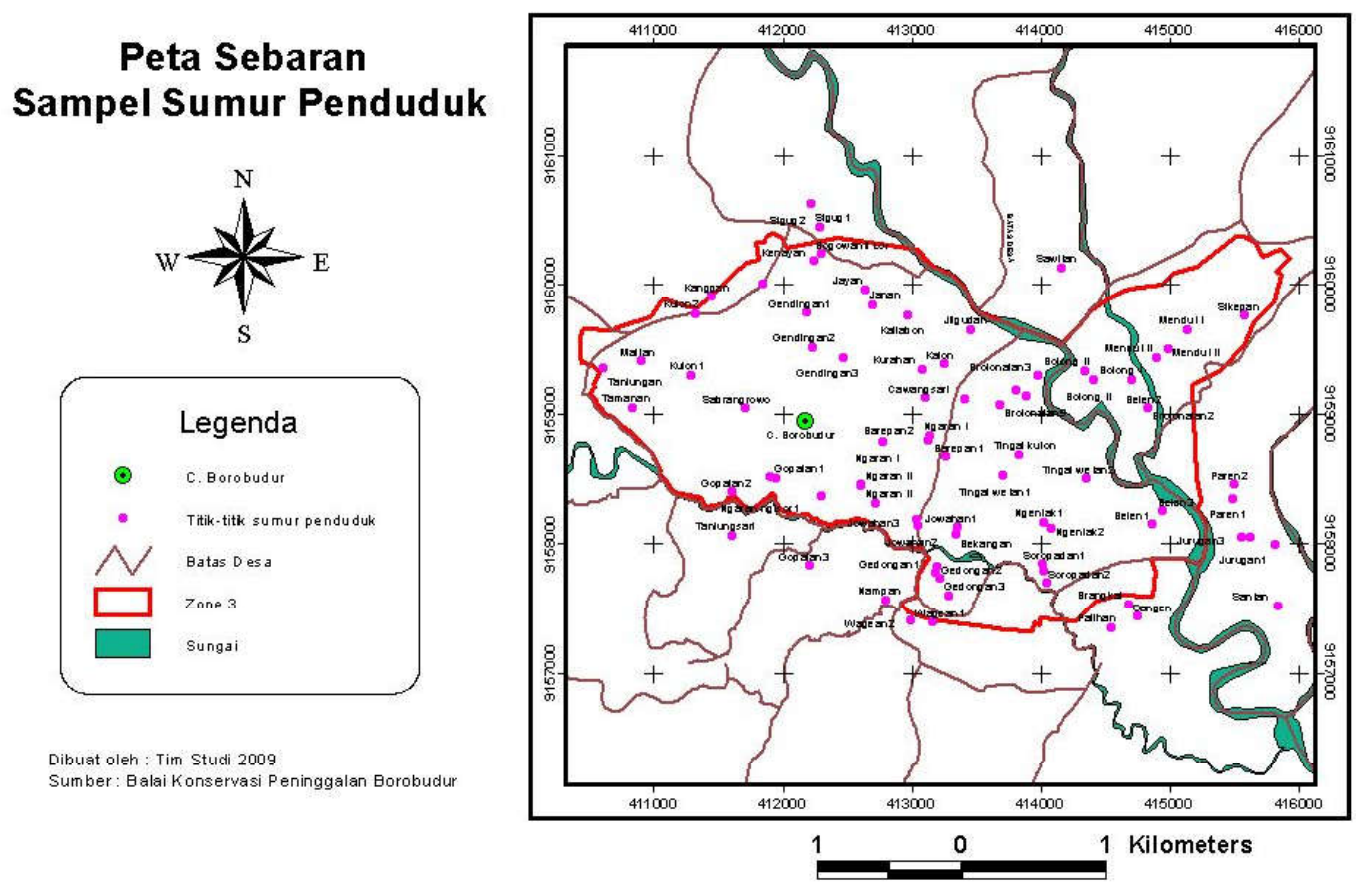

Gambar 1. Peta Sebaran Sampel Sumur Penduduk Pembuatan peta kontur air tanah menggunakan data ketinggian tempat/kontur tanah dari peta topografi digital yang dipunyai oleh Kantor Balai Konservasi Peninggalan Borobudur. Peta topografi digital yang dipakai adalah keluaran d $\begin{array}{llll}\text { a } & \mathrm{r} & \mathrm{i}\end{array}$ BAKOSURTA NAL tahun 2003. Dalam peta topografi digital tersebut terdapat kontur

menunjukkan titik-titik sumur penduduk yang tersebar di beberapa desa di Zona 3, paling besar tersebar di 3 desa yaitu Desa Borobudur, Desa Wanurejo dan Desa Mendut. Dari peta tersebut nampak beberapa titik yang tidak tanah skala 1:25.000 yang mempunyai interval konturnya 12,5 meter. Sebenarnya peta tersebut kurang detail untuk pemetaan air tanah dan butuh skala yang lebih besar, akan 
tetapi karena data yang tersedia dari Bakosurtanal untuk sementara ini hanya skala 1:25.000 maka data tersebut tetap digunakan.

Pembuatan peta kontur air tanah ini diolah dengan menggunakan software ArcGIS 9.3. Setelah peta kontur air tanah dibuat maka selanjutnya dapat dibuat pola aliran air tanah di kawasan Borobudur. Dari hasil penelitian di lapangan menunjukkan bahwa kedalaman muka air tanah di Candi Borobudur berkisar antara 6,5 -7 meter. Angka ini menunjukkan kedalaman air tanah di daerah datar di sekitar bukit Borobudur, bukan di bukitnya karena di bukit Borobudur tidak ada sumur yang bisa diambil datanya. Berdasarkan Sampurno (1973), ketinggian bukit Borobudur dari permukaan datar di sekitarnya sampai halaman candi adalah kurang lebih 15 $\mathrm{m}$, jadi dari penelitian ini kedalaman air tanah di bukit Borobudur adalah sekitar 21,5-22 meter. Hal ini sejalan dengan perkiraan Sampurno (1969) yang menyebutkan bahwa kedalaman muka air tanah di komplek candi adalah sekitar 20-25 meter di bawah permukaan halaman candi. Berdasarkan Sampurno (1969), semua air yang terkandung pada tanah dasar Candi Borobudur (tanah urug dan horison A-C) terletak pada zona aerasi dan di

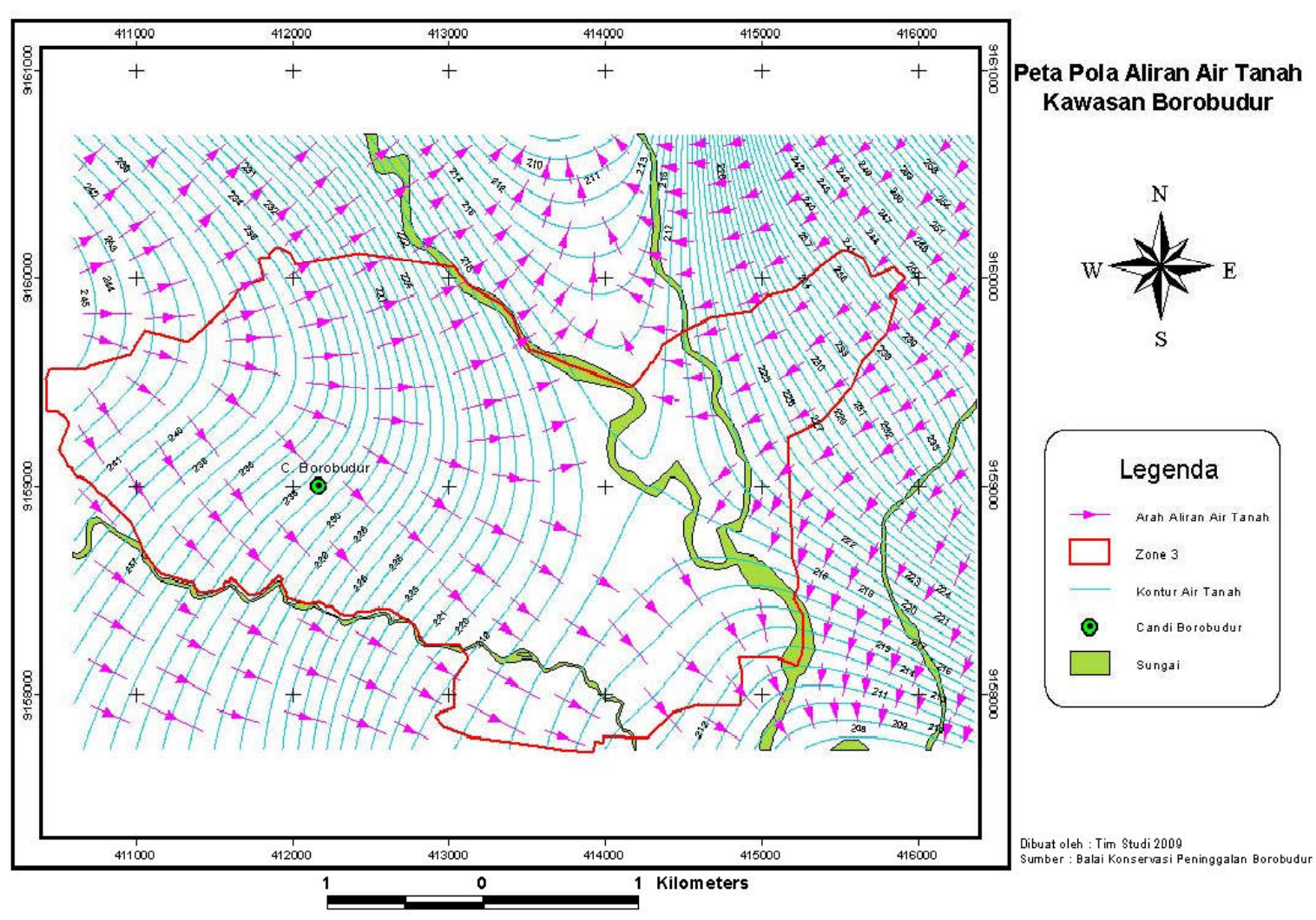

Gambar 2. Peta Pola Aliran Air Tanah Kawasan Borobudur

Borobudur ini diperkirakan mempunyai debit yang kecil dan fluktuasinya besar. Dengan demikian air tanah secara langsung tidak berpengaruh pada kerusakan-kerusakan yang terjadi pada bangunan candi.

Gambar 2. menunjukkan adanya flownets yaitu suatu peta atau konstruksi yang berisikan peta kontur air tanah (equipotential line) dan peta aliran air tanah (streamlines). Secara alami, aliran air tanah akan memotong tegak lurus $\left(90^{\circ}\right)$ kontur air tanah pada kondisi akuifer yang homogen dan isotropis karena pengaruh potensial grafitasi dan mempunyai arah aliran dari muka air tanah (bydraulic head) tinggi menuju air tanah yang lebih rendah.

Berdasarkan peta pola aliran air tanah kawasan Borobudur, pada area di sekitar Candi Borobudur air tanah mengalir dari arah barat laut menuju ke arah tenggara sampai ke Sungai Progo. Sedangkan di daerah Mendut air tanah mengalir dari arah timur laut menuju ke arah barat daya, yang selanjutnya mengarah ke utara setelah memotong Sungai Elo. Pada daerah sebelah selatan mendut, pola air tanahnya mengalir dari arah timur laut berbelok menuju ke arah selatan. Di kawasan yang terletak di antara Sungai Progo dan Elo, air tanah mengalir ke arah utara. Untuk lebih jelasnya lihat Gambar 2. di bawahini.

L o k a s i penelitian pola aliran air tanah ini ternyata me $1 \mathrm{intas}$ i sungai-sungai, sehingga bisa d i 1 i h a t hubungan air tanah dengan sungai tersebut. Untuk Sungai Progo bagian utara arah aliran air tanahnya dari barat daya menuju ke arah timur laut $\mathrm{ke} \mathrm{mudia} \mathrm{n}$ berbelok ke utara. Dilihat dari alirannya, di sebelah barat atas zona saturasi, sehingga kedalaman air tanah di bukit Candi Borobudur tidak diketahui karena pemboran tidak mencapai zona saturasi. Air tanah di bukit Candi
Sungai Progo disebut aliran efluen yaitu sungai menerima air dari air tanah, sedang di sebelah timur Sungai Progo 
disebut aliran influen yaitu sungai mengeluarkan air kepada air tanah. Untuk Sungai Elo, arah aliran air tanahnya dari arah timur menuju ke arah barat lalu berbelok ke utara. Di sebelah timur Sungai Elo disebut aliran efluen dan di sebelah barat sungai disebut aliran influen. Gambar 2. adalah gambaran pola aliran air tanah di kawasan Borobudur. Dengan diketahuinya arah aliran air tanah ini akan bisa berguna untuk analisa selanjutnya, sebagai contoh apakah ada pencemaran air melalui air tanah. Sampai saat ini belum ada penelitian tentang air tanah di kawasan Borobudur khususnya di Candi Borobudur, karena tidak adanya data sumur dan peralatan yang memadai. Selama ini pengukuran muka air tanah di Candi Borobudur menggunakan alat inklinometer yang sebenarnya bukan fungsinya untuk mengukur air tanah melainkan untuk mengukur pergerakan horison dari tanah bukit Candi Borobudur.

Untuk mengetahui kondisi air tanah yang sebenarnya di Candi Borobudur perlu dibuat sumursumur penelitian dan peralatan yang mendukung, agar air tanah bisa dimonitor secara terus menerus dan berkesinambungan.

\section{G. Kesimpulan dan Saran}

\section{a. Kesimpulan}

1. Berdasarkan hasil penelitian, untuk kedalaman muka air tanah di bukit Candi Borobudur adalah sekitar 21,5 - 22 meter, sejalan dengan perkiraan Sampurno (1969) yang memperkirakan kedalaman air tanah 20 -25 meter dari permukaan halaman candi.

2. Pola aliran air tanah di sekitar Candi Borobudur mengalir dari arah barat laut ke arah tenggara sampai Sungai Progo. Sedangkan di daerah Mendut, air tanahnya mengalir dari arah timur laut menuju ke arah barat daya. Di area selatan Mendut aliran air tanahnya dari timur laut berbelok ke arah selatan.

3. Dua sungai besar di wilayah penelitian yaitu Sungai Progo dan Sungai Elo mempunyai 2 sifat aliran sekaligus yaitu aliran efluen (sungai menerima air dari air tanah) dan aliran influen (sungai mengeluarkan air kepada air tanah).

\section{b. Saran}

1. Perlu adanya percobaan pengeboran di sekitar Candi Borobudur untuk medapatkan data tentang air tanah yang selama ini belum ada data mengenai air tanah di sekitar Candi Borobudur, sehingga bisa dilakukan monitoring air tanah secara kontinu dan berkesinambungan.

2. Penelitian mengenai geologi tanah di sekitar Candi Borobudur secara detail perlu dilakukan penting hubungannya dengan studi air tanah.

3. Perlu diadakan penelitian serupa yang dilakukan pada musim penghujan agar dapat dibandingkan kondisi air tanahnya dengan musim kemarau seperti hasil dari penelitian ini.

\section{DAFTAR PUSTAKA}

Ersin Seyhan, 1977, Dasar-dasar Hidrologi, Universitas Gadjah Mada, Yogyakarta

Ir. Hendy Soesilo, dkk, 2001, Laporan Studi Masalah Air Tanah Pada Candi Borobudur (Studi Air Permukaan-Tahap II), Balai Konservasi Peninggalan Borobudur

Ir. Joko Luknanto,M.Sc.,Ph.D, dkk, 2002, Evaluasi Stabilitas Sub Struktur, Magelang

JICA,1979, Masterpan Borobudur Archaeology Park, Jakarta: Pemerintah Republik Indonesia.

Sampurno, 1969, Pelita Borobudur, Seri B No. 3, Penelitian Tanah Dasar Candi Borobudur, Penugasan dari Lembaga Purbakala dan Sejarah Restorasi Borobudur, Laporan Kegiatan Proyek PELITA Restorasi Candi Borobudur, Departemen Pendidikan dan Kebudayaan

Sampurno, 1973, Pelita Borobudur, Seri B No.1, Penelitian Tanah Candi Borobudur, Laporan Kegiatan Proyek PELITA Restorasi Candi Borobudur, Departemen Pendidikan dan Kebudayaan

Suhartono, Yudi, 2008, Pelestarian Sumberdaya Arkeologi Dalam Konteks Keruangan di Kawasan Borobudur, Tesis, Program Studi Arkeologi Program Pasca Sarjana, Jogjakarta : Program Pasca Sarjana UGM

Todd, 1980, Groundwater Hydrology, Second Edition, University of Califonia, Berkeley: John Wiley and Sons, New York

Van Bemmelen, R.W., 1949, The Geology of Indonesia, vol.IA, General Geology, Government Printing Office, The Hague Martinus Nijnhoff 